\title{
Co-infection of Influenza B and Streptococci causing severe pneumonia and septic shock in healthy women
}

Timothy Aebi ${ }^{1,2^{*}}$, Maja Weisser ${ }^{3}$, Evelyne Bucher ${ }^{1}$, Hans H Hirsch ${ }^{3,4}$, Stephan Marsch' ${ }^{1}$, Martin Siegemund ${ }^{1,2}$

\begin{abstract}
Background: Since the Influenza A pandemic in 1819, the association between the influenza virus and Streptococcus pneumoniae has been well described in literature. While a leading role has been so far attributed solely to Influenza A as the primary infective pathogen, Influenza B is generally considered to be less pathogenic with little impact on morbidity and mortality of otherwise healthy adults. This report documents the severe synergistic pathogenesis of Influenza B infection and bacterial pneumonia in previously healthy persons not belonging to a special risk population and outlines therapeutic options in this clinical setting.

Case Presentation: During the seasonal influenza epidemic 2007/2008, three previously healthy women presented to our hospital with influenza-like symptoms and rapid clinical deterioration. Subsequent septic shock due to severe bilateral pneumonia necessitated intensive resuscitative measures including the use of an interventional lung assist device. Microbiological analysis identified severe dual infections of Influenza B with Streptococcus pyogenes in two cases and Streptococcus pneumoniae in one case. The patients presented with no evidence of underlying disease or other known risk factors for dual infection such as age (< one year, $>65$ years), pregnancy or comorbidity.

Conclusions: Influenza B infection can pose a risk for severe secondary infection in previously healthy persons. As patients admitted to hospital due to severe pneumonia are rarely tested for Influenza B, the incidence of admission due to this virus might be greatly underestimated, therefore, a more aggressive search for influenza virus and empirical treatment might be warranted. While the use of an interventional lung assist device offers a potential treatment strategy for refractory respiratory acidosis in addition to protective lung ventilation, the combined empiric use of a neuraminidase-inhibitor and antibiotics in septic patients with pulmonary manifestations during an epidemic season should be considered.
\end{abstract}

\section{Background}

As early as 1903, French physician R. T. H. Laennec noted that the prevalence of pneumonia increased following an influenza epidemic [1]. This association between the influenza virus and Streptococcus pneumoniae became most obvious during the Influenza A pandemic of 1918, during which an estimated 40 to 50 million, mostly young and otherwise healthy people died, probably due to secondary bacterial pneumonia. Several reviews in the years after the pandemic led to the conclusion that bacteria were secondary pathogens and not the primary affecting agents [2].

\footnotetext{
* Correspondence: aebit@uhbs.ch

${ }^{1}$ Medical Intensive Care Unit, University Hospital Basel, Basel, Switzerland

Full list of author information is available at the end of the article
}

There is evidence that the majority of deaths in the 1919 and subsequent 1957 and 1968 pandemics resulted directly from secondary bacterial pneumonia caused by common upper respiratory tract bacteria. These findings indicate, that addressing the viral cause alone by antiviral therapy and vaccination might not be sufficient, leading to a serious debate on pre-emptive empirical antibiotic therapy to cover the possibility of life-threatening secondary bacterial infections $[3,4]$. In regards of pandemic influenza planning, the importance of treating bacterial complications might be significantly higher in developing countries as neuraminidase inhibitors and vaccines might not be available to the majority of people [5]. 
So far a leading role has been attributed solely to Influenza $A$ as the primary infective pathogen, while Influenza $B$ is generally considered to be less pathogenic, having little impact on morbidity and mortality of otherwise healthy adults. We report for the first time severe secondary bacterial pneumonia with septic shock following infection with Influenza B in previously healthy women presenting to our hospital during the influenza season 2007/2008.

\section{Case Presentation}

\section{Patient 1}

A 39-year-old, previously healthy woman presented to the emergency unit with a 3-day history of myalgia, chills, high fever and a sore throat as well as vomitus, diarrhea and headaches. She was febrile, tachypnoeic with a respiratory rate of 40 per minute and showed an oxygen saturation of $92 \%$ despite receiving 10 litres of oxygen via face mask. She was tachycardic and hypotensive, indicating a septic shock. A patchy exanthema was visible on her trunk, and rales were noted upon bilateral auscultation. Her laboratory findings revealed a leucopenia of $2.9 \times 10^{-9} / \mathrm{l}$, a CRP of $507 \mathrm{mg} / \mathrm{l}$ and a procalcitonin of $139 \mathrm{ng} / \mathrm{ml}$ (Table 1). A chest $\mathrm{x}$-ray showed diffuse infiltrates bilaterally.

Blood cultures and expectorate were taken, and antibiotic therapy was initiated with intravenous ceftriaxone $2 \mathrm{~g} /$ day. Due to further respiratory deterioration, the patient was intubated. Aggressive volume replacement and high dose vasopressors were needed to stabilize the hypotensive shock. Haemofiltration was started for acute renal failure. After a diagnostic bronchoscopy with bronchoalveolar lavage on the day of admission, the antibiotic therapy was empirically changed to piperacillin/tazobactam $4.5 \mathrm{~g} 3$ times daily and clarythromycin $500 \mathrm{mg}$ twice daily. Oseltamivir $75 \mathrm{mg}$ twice daily was added for 5 days, as the history was suspicious for influenza disease with bacterial superinfection. Due to progressive, refractory hypercapnia and respiratory acidosis, an interventional lung assist device (iLA membrane ventilator, Nova Lung ${ }^{\oplus}$, Talheim, Germany) was installed the same day. ${ }^{3}$

Group A streptococci grew in four (of four drawn) blood cultures as well as in the bronchoalveolar lavage fluid. Taking the clinical picture into account, a streptococcal toxic shock syndrome was diagnosed, and the antibiotic therapy was changed to high-dose penicillin (5 Mio U four times a day). Clindamycin $900 \mathrm{mg}$ three times daily was added to prevent toxin production for 3 days. A 5 day immunoglobulin therapy (Redimmune $0.4 \mathrm{~g} / \mathrm{kg} / \mathrm{d}$ ) was started. The bronchoalveolar lavage was repeated 5 days after admission to look for viral pathogens and confirmed the presence of Influenza B by real-time polymerase chain reaction (RT-PCR4) with 40,565 copies/ml (Table 1 ).

Over the following days, a nosocomial, ventilatorassociated pneumonia was diagnosed and the antibiotic therapy was empirically changed to imipenem $500 \mathrm{mg}$ four times a day. Methicillin susceptible Staphylococcus aureus was detected by culture of respiratory samples. Following clinical improvement, the lung assist device was removed after 11 days and the antibiotic therapy was stopped after 14 days. A third episode of respiratory deterioration occurred 2 weeks after admission. No pathogen could be isolated from bronchoalveolar lavage. The recurrence of severe respiratory acidosis due to refractory hypercarbia required another lung assist device, and a dilatational tracheotomy was performed.

After 24 days of intensive care, the patient's condition had finally improved enough for the lung assist device to be removed; the patient was weaned successfully and decanulated on day 35 . The patient was transferred to a rehabilitation facility with mild critical illness polyneuropathy. She showed no neurological deficits otherwise.

\section{Patient 2}

A previously healthy 27-year-old woman presented with complaints of an influenza-like infection with sore throat, fever and dry coughs since three days. The night before admission her sore throat became worse, fever climbed to $39^{\circ} \mathrm{C}$ and she complained of headaches. On admission, she was clinically diagnosed as having influenza, received intravenous fluids, and her discharge was planned thereafter. Within 8 hours post admission, her general condition deteriorated rapidly, showing progressive hypotension and respiratory failure. She was alert but in a bad general condition, fulfilling all criteria of a septic shock. Her laboratory findings on admission showed a leukocyte count of $12 \times 10^{-9} /$ l, a CRP of 103 $\mathrm{mg} / \mathrm{l}$ and a procalcitonin level of $34 \mathrm{ng} / \mathrm{ml}$ (Table 1 ). A chest $\mathrm{x}$-ray showed infiltrations in the right lung consistent with pneumonia. After blood cultures were drawn, an antibiotic therapy with amoxicillin/clavulanic acid 2.2 $\mathrm{g}$ three times daily and clarithromycin $500 \mathrm{mg}$ twice daily was initiated and crystalloids and high dose catecholamines had to be applied. Due to respiratory failure, the patient was intubated. On the next morning, a marked pleural effusion with $1000 \mathrm{ml}$ of exudative fluid was drained. Despite all these measures, her respiratory situation became worse with refractory hypoxaemia and increasing ventilation pressures, compelling us to install an interventional lung assist device. After this, her situation stabilized markedly. To this point, no other organ failures had occurred.

Streptococcus pyogenes grew in all four blood cultures drawn at admission and from the bronchoalveolar 
Table 1 Characteristics of three previously healthy patients with primary Influenza B infection, severe bacterial pneumonia and septic shock

\begin{tabular}{|c|c|c|c|}
\hline Characteristic & Patient 1 & Patient 2 & Patient 3 \\
\hline Date of admission & February 2008 & March 2008 & March 2008 \\
\hline Days of hospitalization & 56 & 18 & 26 \\
\hline Age (years) & 40 & 27 & 61 \\
\hline Co-morbidities & None & None & Osteoporosis \\
\hline \multicolumn{4}{|l|}{ Septic shock * } \\
\hline Tachycardia (beats/min) & 160 & 120 & 110 \\
\hline Tachypnoea (rate/min) & 40 & 45 & 30 \\
\hline Hypotension & Yes & Yes & Yes \\
\hline Fever $\left({ }^{\circ} \mathrm{C}\right)$ & 40 & 39 & 39 \\
\hline Leukocyte count ( ×10S9/I) & 2.96 & 12.4 & 14.2 \\
\hline \multicolumn{4}{|l|}{ Microbiology } \\
\hline Initially isolated bacteria & S. pyogenes ${ }^{\dagger}$ & S. pyogenes ${ }^{\dagger}$ & S. pneumoniae ${ }^{\ddagger}$ \\
\hline Influenza B RT-PCR ${ }^{\S}$ & Positive & Positive & Positive \\
\hline Influenza A RT-PCR ${ }^{\S}$ & Negative & Negative & Negative \\
\hline Initial therapy & Piperacillin/Tazobactam & Amoxicillin/clavulanic acid plus Clarithromycin & Ceftriaxon plus Clarithromycin \\
\hline \multirow[t]{2}{*}{ Final therapy } & Penicllin plus & Penicillin plus & Vancomycin plus \\
\hline & Oseltamivir & Oseltamivir & Oseltamivir \\
\hline \multicolumn{4}{|l|}{ Laboratory findings $\|$} \\
\hline CRP $(\mathrm{mg} / \mathrm{l})$ & 507 & 445 & 329 \\
\hline PCT (ng/ml) & 203 & 113 & 3.71 \\
\hline \multicolumn{4}{|l|}{ Arterial blood gas $\|$} \\
\hline $\mathrm{pH}$ & 7.19 & 7.28 & 7.45 \\
\hline $\mathrm{paO} 2(\mathrm{kPa})$ & 8.7 & 9.72 & 6.59 \\
\hline $\mathrm{paCO} 2(\mathrm{kPa})$ & 8.9 & 4.84 & 4.95 \\
\hline $\mathrm{BE}$ & -4.6 & -8.8 & 2.5 \\
\hline Lactate (mmol/l) & 1.4 & 5.1 & 2.5 \\
\hline Death on day & - & 18 & - \\
\hline
\end{tabular}

* Defined as patients showing all of following abnormal findings: tachycardia, tachypnoe, fever, leukocytosis or -penia and hypotension. Data printed are from the time of admission.

${ }^{+}$Results from bronchoalveolar lavage and blood cultures.

₹ Result from urine pneumococcal antigen test.

$\S$ Real-time quantitative PCR from tracheal aspirate detecting Influenza A and B in separate reactions confirmed in at least two separate exams.

" Values showing the greatest deviation from normal during the first two days after admission. All blood gas data were obtained while applying high flow oxygen through a non re-breathing mask.

lavage. RT-PCR of the bronchoalveolar lavage for Influenza B was positive with 3,568 copies $/ \mathrm{ml}$ and suggested a primary influenza infection with bacterial super infection (Table 1). Antibiotic treatment was changed to high-dose penicillin ( 5 Mio $U$ four times a day) and oseltamivir $75 \mathrm{mg}$ twice daily was added (on day 5 after admission) for 5 days. On day seven, ventilator associated pneumonia was suspected and bronchoalveolar lavage repeated. No causative agent was identified, and another Influenza RT-PCR was negative for Influenza B.

Fifteen days after admission, a sudden respiratory deterioration occurred with pulmonary hemorrhage, compounding mechanical ventilation markedly. A bronchoscopy showed crustal lesions in the trachea but no active bleeding. On suspicion of pneumothoraces, thoracic drainages were inserted bilaterally. A malfunction of the interventional lung assist device made a change of the device necessary. The invasive procedure was poorly tolerated, and temporary mechanical resuscitation had to be performed. Thereafter, the patient remained dependant on high dose catecholamines and showed persistent signs of cerebral hypoxaemia. The patient died 18 days after admission. Autopsy was declined by the family for religious reasons.

\section{Patient 3}

A 61-year-old previously healthy woman was admitted to hospital after returning from a one week of holiday 
in Morocco. She complained of headaches, a sore throat, no appetite and general weakness since 9 days, and mentioned having diarrhoea since 6 days. She was started on amoxicillin $750 \mathrm{mg}$ three times daily by a family doctor without effect. The day she presented to our emergency unit she was febrile with $38^{\circ} \mathrm{C}$ and tachypnoeic. Auscultation detected rales bilaterally and bilateral infiltrates were found on a chest $\mathrm{x}$-ray. Her laboratory findings showed a leukocyte count of $14 \times 10^{-9} / 1$ and a CRP of $195 \mathrm{mg} / \mathrm{l}$ initially (Table 1 ). An empiric antibiotic therapy with ceftriaxone $2 \mathrm{~g}$ /day and clarythromycin $500 \mathrm{mg}$ twice daily was initiated, and the septic patient was transferred to the intensive care unit. The pneumococcal antigen was positive in the urine sampled on admission. Blood cultures remained negative, which may be explained by the antibiotic pretreatment. A direct influenza antigen test was negative initially.

Due to respiratory failure, the patient was intubated on day 4 despite non-invasive ventilation. A spontaneous right-sided pneumothorax was treated with a thoracic drainage. Over the next few hours, her respiratory situation deteriorated further showing a progressive hypoxaemia and a reduced lung compliance requiring an interventional lung assist device. With the suspicion of penicillin-resistant pneumococci in this patient returning from Morocco, the antibiotic therapy was changed to vancomycin $1 \mathrm{~g}$ twice daily. A second urine test for pneumococcal antigen was again positive. No other bacteria was detected in a bronchial alveolar lavage five days after admission, but RT-PCR from a bronchial alveolar lavage on day 5 revealed Influenza B with 12,231 copies/ml (Table 1). Oseltamivir $75 \mathrm{mg}$ twice daily was added (on day 9 after admission) for 5 days, and the RT-PCR repeated thereafter remained positive with 13,363 copies/ml for Influenza B. Seven days after admission, the pulmonary situation had stabilized enough that the interventional lung assist device could be safely removed. One day later she was extubated. The patient was transferred to a rehabilitation facility 26 days after admission.

This is the first report of Influenza B infections accompanied by severe bacterial superinfection in three healthy women.

Fatal co-infections of influenza virus with Streptococcus pneumoniae have been described in mice since the early eighties [6], and have been reported following in clinical outbreaks [7]. In addition to S. pneumoniae, the most common co-infecting bacteria are Staphylococcus aureus, Haemophilus influenzae, Streptococcus pyogenes and Mycoplasma pneumoniae. Pathophysiologically various data from mice models suggests that influenza virus infection damages the epithelium of the bronchi and lungs, allowing microaspirated bacterial pathogens to establish infection [8]. On the other hand, influenza alters the local immunity [9] and the inflammatory response [10-12] facilitating the outgrowth of bacteria. Underlying immunosuppression might lead to more severe and prolonged disease [13]. Our patients presented with no evidence of underlying disease or other known risk factors for dual infection such as age $(<$ one year, $>65$ years), pregnancy or comorbidity [14].

From an epidemiological viewpoint, the circulating strain is known to contribute to mortality with H3N2 subtype causing more influenza-associated deaths than H1N1 or influenza B viruses [15]. Influenza B leads to fewer co-infections [16] and milder disease compared to Influenza A [8,17]. In Switzerland, the seasonal influenza epidemics of 2007/2008 were characterized by an initial increase in Influenza A H3N2 cases, whereas in the later months, when our patients presented, infections with Influenza B prevailed [17] (Figure 1). The predominant circulating B strain in Switzerland was B/Jiangsu/10/03. This strain was not matched by a corresponding strain in the $\mathrm{B}$ component of the vaccine and was not present in the previous year (Figure 2), therefore, it is possible that there is no immunologic memory for this infection, perhaps contributing to the severity of infection [18]. The first and second patient had young children suffering from influenza-like symptoms and most probably transmitted the virus to their mother. In general, we do not think that there is an association between sex and disease severity. While pregnancy was associated with poor outcome in the H1N1 pandemics, none of our patients was pregnant.

Diagnosis in our cases was based on real-time quantitative PCR, according to a previously published protocol detecting Influenza A and B in separate reactions with a limit of detection of $2.5 \log 10$ copies/ml [19]. This method is known to be very sensitive and specific compared to antigen testing, which is a more rapid but less sensitive test, and was negative in one of our three patients. Severe cases of Influenza B have probably always occurred. But as most routine laboratories did no specific testing for Influenza B, this could not be documented until recently. Interestingly, a recent study on the effect of oseltamivir in patients hospitalized with Influenza infection included 215 patients with influenza $\mathrm{B}$, of which 13 died, confirming our data on serious courses of Influenza B infections [20].

All three patients received oseltamivir, a highly selective neuraminidase-inhibitor. This agent is effective against Influenza A and B. Although clinical data are limited in Influenza B, some evidence exists that oseltamivir might have less effect on Influenza B, therefore, higher dosing may be necessary [21]. Patient 1 received an early empiric treatment with oseltamivir, as her history was indicative for primary influenza infection and 


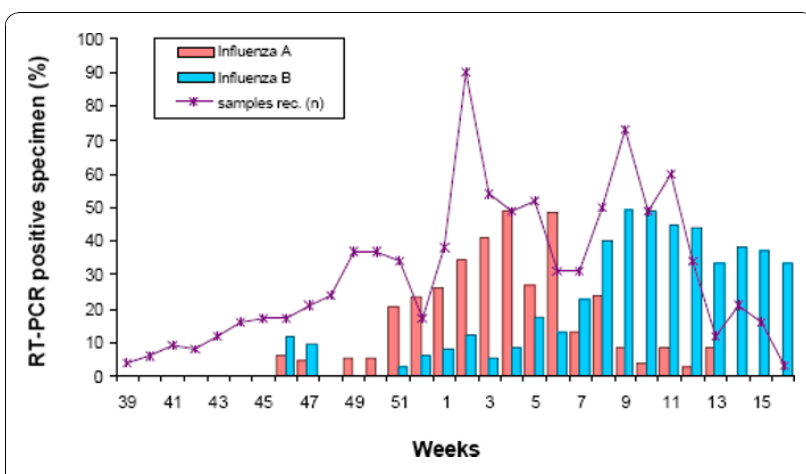

Figure 1 Distribution of influenza subtypes recorded by the influenza surveillance sentinel network in Switzerland (Season $2007-2008)^{15}$.

bacterial superinfection. In the other two patients, antiviral treatment was started only later, on day 5 in the second and at day 9 in the third patient. Given the fact that antiviral treatment is efficacious especially in the early course, empirical use of oseltamivir in severe pneumonia during an influenza season might be advisable, even though PCR-testing is a highly sensitive and reasonably rapid. With regard to oseltamivir's properties and the fact that septic patients are immunocompromised per se, the early use of neuraminidase-inhibitors seems warranted. In fact, our case series favours the approach of empirical combined antiviral-antibiotic treatment, a discussion that evolved during the H1N1 pandemics. However, there is no evidence that the use of oseltamivir yields any benefit after 48 hours of infection.

Supportive care measures for septic shock and respiratory failure were taken immediately. Minimal inhibitory concentrations for penicillin were low in the two cases with S. pyogenes indicating full susceptibility towards the administered empirical betalactam antibiotic. To prevent

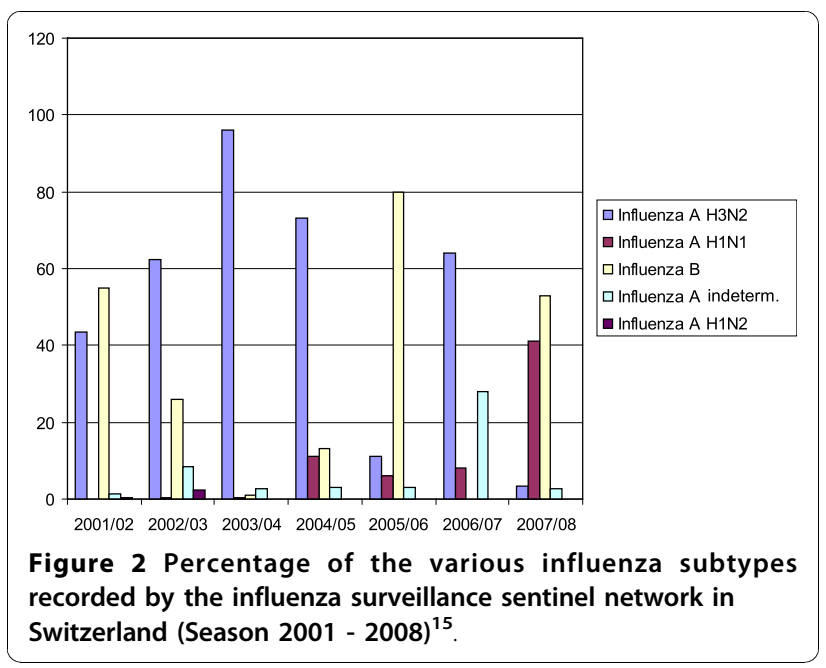

toxin production, clindamycin was added. S. pyogenes is known to cause fulminant toxic shock syndromes, for which both patients qualify, occurring also in young and previously healthy persons [22]. In the third case, no resistance testing was available due to diagnosis of $S$. pneumoniae by means of a non-cultural assay only. A penicillin-resistant strain might have been possible in the patient returning from Morocco, where the local epidemiology shows up to $40 \%$ penicillin-resistant pneumococci [23] and, therefore, may have contributed to delay in a correct antibiotic treatment.

The application of an interventional lung assist enables a safe application of lung protective ventilation [24] together with a therapy of respiratory acidosis in patients where all other intensive care measures have failed to provide adequate ventilation and decarboxylation. Although uncommonly used on our ward, the lung assist device allowed us to combine very low tidal volumes $(3-6 \mathrm{ml} / \mathrm{kg})$ and high PEEP levels with lower plateau pressures and, thus, the avoided barotraumas reported in these patients. Especially during acute lung injury due to pneumonia, the application of low tidal ventilation may prevent secondary injury from mechanical ventilation to the uninfected parts of the lung.

\section{Conclusions}

Influenza B infection can pose a risk for severe secondary infection in previously healthy persons. As patients admitted to hospital due to severe pneumonia are rarely tested for Influenza B, the incidence of admission due to this virus might be greatly underestimated, therefore, a more aggressive search for influenza virus and empirical treatment might be warranted. While the use of an interventional lung assist device offers a potential treatment strategy for refractory respiratory acidosis in addition to protective lung ventilation, the combined empiric use of a neuraminidase-inhibitor and antibiotics in septic patients with pulmonary manifestations during an epidemic season should be considered.

\section{Acknowledgements}

Written consent was obtained from the patient or their relative for publication of study. We thank Dr. Karoline Aebi-Popp for providing additional information on infections in women and Allison Dwileski for copyediting the manuscript.

\footnotetext{
Author details

${ }^{1}$ Medical Intensive Care Unit, University Hospital Basel, Basel, Switzerland. ${ }^{2}$ Department of Anesthesia and Surgical Intensive Care, University Hospital Basel, Basel, Switzerland. ${ }^{3}$ Division of Infectious Diseases and Hospital Epidemiology, University Hospital Basel, Basel, Switzerland. ${ }^{4}$ Institute for Medical Microbiology, Department of Biomedicine, University of Basel, Basel, Switzerland.
}

\section{Authors' contributions}

$T A, E B, S M$ and MS identified the patients, reviewed their patient charts and performed a literature research. MW and HHH worked off the infectiological 
background and provided figure 1 and figure 2. MS provided additional information on interventional lung assist devices. TA drafted the manuscript. All authors read and approved the final version of the manuscript.

\section{Competing interests}

The authors declare that they have no competing interests.

Received: 25 February 2010 Accepted: 27 October 2010 Published: 27 October 2010

\section{References}

1. Laennec RT: De l'auscultation mediate. New York; 1923.

2. Jordan EO: Epidemic influenza: A Survey. Am Medical Ass 1927, 356-438.

3. Morens DM, Taubenberger JK, Fauci AS: Predominant role of bacterial pneumonia as a cause of death in pandemic influenza: implications for pandemic influenza preparedness. J Infect Dis 2008, 198(7):962-970.

4. Brundage JF, Shanks GD: Deaths from bacterial pneumonia during 191819 influenza pandemic. Emerg Infect Dis 2008, 14(8):1193-1199.

5. Gupta RK, George R, Nguyen-Van-Tam JS: Bacterial pneumonia and pandemic influenza planning. Emerg Infect Dis 2008, 14(8):1187-1192.

6. McCullers JA, Rehg JE: Lethal synergism between influenza virus and Streptococcus pneumoniae: characterization of a mouse model and the role of platelet-activating factor receptor. J Infect Dis 2002, 186(3):341-350.

7. O'Brien KL, Walters MI, Sellman J, Quinlisk P, Regnery H, Schwartz B, Dowell SF: Severe pneumococcal pneumonia in previously healthy children: the role of preceding influenza infection. Clin Infect Dis 2000 30(5):784-789.

8. McCullers JA: Insights into the interaction between influenza virus and pneumococcus. Clin Microbiol Rev 2006, 19(3):571-582.

9. Abramson JS, Mills EL, Giebink GS, Quie PG: Depression of monocyte and polymorphonuclear leukocyte oxidative metabolism and bactericidal capacity by influenza A virus. Infect Immun 1982, 35(1):350-355.

10. van der Sluijs KF, Nijhuis M, Levels JH, Florquin S, Mellor AL, Jansen HM, van der Poll T, Lutter R: Influenza-induced expression of indoleamine 2,3dioxygenase enhances interleukin-10 production and bacterial outgrowth during secondary pneumococcal pneumonia. J Infect Dis 2006, 193(2):214-222.

11. Zhang WJ, Sarawar S, Nguyen P, Daly K, Rehg JE, Doherty PC, Woodland DL, Blackman MA: Lethal synergism between influenza infection and staphylococcal enterotoxin B in mice. J Immunol 1996, 157(11):5049-5060.

12. Gong JH, Sprenger $\mathrm{H}$, Hinder F, Bender A, Schmidt A, Horch S, Nain M, Gemsa D: Influenza A virus infection of macrophages. Enhanced tumor necrosis factor-alpha (TNF-alpha) gene expression and lipopolysaccharide-triggered TNF-alpha release. J Immunol 1991, 147(10):3507-3513.

13. Nichols WG, Guthrie KA, Corey L, Boeckh M: Influenza infections after hematopoietic stem cell transplantation: risk factors, mortality, and the effect of antiviral therapy. Clin Infect Dis 2004, 39(9):1300-1306.

14. Rothberg MB, Haessler SD, Brown RB: Complications of viral influenza. Am $J$ Med 2008, 121(4):258-264.

15. Thompson WW, Shay DK, Weintraub E, Brammer L, Cox N, Anderson LJ, Fukuda K: Mortality associated with influenza and respiratory syncytial virus in the United States. Jama 2003, 289(2):179-186.

16. Mancini DA, Alves RC, Mendonca RM, Bellei NJ, Carraro E, Machado AM, Pinto JR, Mancini Filho J: Influenza virus and proteolytic bacteria coinfection in respiratory tract from individuals presenting respiratory manifestations. Rev Inst Med Trop Sao Paulo 2008, 50(1):41-46.

17. Saisonale Grippe 2007/08. Epidemiologie, Virologie, Impfstoffversorgung und -zusammensetzung. BAG Bulletin 2008, 24:419-423.

18. Simonsen L, Clarke MJ, Williamson GD, Stroup DF, Arden NH, Schonberger LB: The impact of influenza epidemics on mortality: introducing a severity index. Am J Public Health 1997, 87(12):1944-1950.

19. van Elden $L$, Nijhuis $M$, Schipper $P$, Schuurman $R$, van Loon AM: Simultaneous detection of influenza viruses $A$ and $B$ using real-time quantitative PCR. J Clin Microbiol 2001, 39(1):196-200.

20. Lee N, Choi KW, Chan PK, Hui DS, Lui GC, Wong BC, Wong RY, Sin WY, Hui WM, Ngai KL, et al: Outcomes of adults hospitalised with severe influenza. Thorax 65(6):510-515.

21. Hurt AC, McKimm-Breschkin JL, McDonald M, Barr IG, Komadina N, Hampson AW: Identification of a human influenza type B strain with reduced sensitivity to neuraminidase inhibitor drugs. Virus Res 2004, 103(1-2):205-211.

22. Davies HD, McGeer A, Schwartz B, Green K, Cann D, Simor AE, Low DE: Invasive group A streptococcal infections in Ontario, Canada. Ontario Group A Streptococcal Study Group. N Engl J Med 1996, 335(8):547-554.

23. Borg MA, van de Sande-Bruinsma N, Scicluna E, de Kraker M, Tiemersma $E_{\text {, }}$ Monen J, Grundmann H: Antimicrobial resistance in invasive strains of Escherichia coli from southern and eastern Mediterranean laboratories. Clin Microbiol Infect 2008, 14(8):789-796.

24. Ventilation with lower tidal volumes as compared with traditional tidal volumes for acute lung injury and the acute respiratory distress syndrome. The Acute Respiratory Distress Syndrome Network. N Engl 」 Med 2000, 342(18):1301-1308

\section{Pre-publication history}

The pre-publication history for this paper can be accessed here: http://www.biomedcentral.com/1471-2334/10/308/prepub

doi:10.1186/1471-2334-10-308

Cite this article as: Aebi et al: Co-infection of Influenza B and Streptococci causing severe pneumonia and septic shock in healthy women. BMC Infectious Diseases 2010 10:308.

\section{Submit your next manuscript to BioMed Central and take full advantage of:}

- Convenient online submission

- Thorough peer review

- No space constraints or color figure charges

- Immediate publication on acceptance

- Inclusion in PubMed, CAS, Scopus and Google Scholar

- Research which is freely available for redistribution

Submit your manuscript at www.biomedcentral.com/submit
C Biomed Central 